\title{
A BELLE ÉPOQUE NOS ELEMENTOS DE ILUMINAÇÃO PUBLICA DE PELOTAS
}

\author{
Ricardo Jaekel dos Santos - PPGMP/ ICH/ UFPEL \\ ricardojaekel@hotmail.com \\ Carlos Alberto Ávila Santos - PPGMP/ ICH/ UFPEL \\ betosant@terra.com.br
}

\section{RESUMO}

O patrimônio vincula-se com a cultura material de um lugar ou região, sua finalidade está em informar às condições e estilo de vida em um passado que reflete no presente, com vistas em preservar informações às gerações futuras. Neste artigo são apresentadas as pesquisas sobre os objetos utilizados na iluminação urbana da cidade de Pelotas-RS. A cidade é reconhecida pela valorização de seu centro histórico, são casarões e seu entorno, esculturas, reservatórios e chafarizes, alguns tombados ou inventariados. Compreendido em um período de efervescência econômica e cultural, a cidade reproduziu um estilo singular de beleza entre o fim do século XIX e início do século XX, caracterizado como "Belle Époque" na França. A iluminação urbana em ferro fundido, um bem agregado aos casarões, participou efetivamente dos avanços tecnológicos e culturais da cidade, entretanto, as informações são escassas, sendo assim, entendeu-se por necessário disponibilizar informações encontradas quanto à origem, estilo e materialidade desses objetos, os quais convergem para representar a Belle Époque pelotense.

Palavras-Chaves: Belle Époque; Cultura material; Ferro fundido; Iluminação Urbana.

\section{INTRODUÇÃO}

Os estudos sobre a cultura material despertam interesses em diversas áreas, historiadores de arte, antropólogos, arqueólogos, arquitetos, museólogos e restauradores. Um objeto pode instigar pesquisas ao portar evidências de transformações sociais, culturais e tecnológicas de um povo. Entretanto, determinados objetos ainda carecem de pesquisas e valorização dentro de um universo de informações encontradas em centros históricos, como no caso da cidade de Pelotas-RS. Esta cidade do sul do Brasil destaca-se pela preservação de casarões do século XIX, faz uso de instrumentos legais para o cadastro (inventário) e proteção (tombamento). Entretanto, estas políticas não costumam ser aplicadas em objetos ou bens agregados aos edifícios construídos, como os utilizados na iluminação pública. 
A iluminação urbana acompanha os avanços tecnológicos, sua presença interfere na vida do indivíduo, grupo e sociedade, interferência que se dá cultural e socialmente. Os acontecimentos do passado podem estar materializados na forma de artefatos, como fotos, documentos, ou objetos que ao serem interpretados, comprovam sua participação no processo de evolução da sociedade. Os lugares e os objetos não fazem morrer a memória, eles participam ativamente de sua estruturação (TURGEON, 2006)

As luminárias encontradas na cidade de Pelotas são o foco deste artigo, são elementos originados de uma época de grandes transformações científicas, que implicaram em novas técnicas advindas da industrialização, como por exemplo, o ferro fundido. A revolução industrial facilitou o acesso aos bens de consumo sofisticados, entre eles objetos destinados à iluminação e, motivou o desejo pelo estilo europeu, sobretudo o francês. No período chamado de Belle Époque, que ocorreu na Europa no final do século XIX e início do XX, diferentes artefatos industrializados difundiram-se rapidamente para outros continentes. No Brasil e, em particular em Pelotas, as importações de produtos modernos comprovam a ambição da sociedade local de copiar a cultura francesa. (Santos 2007).

\section{O ESTILO E SUA IMPORTAÇÃO}

O final do século XIX e início do XX foi um período de destaque com grandes transformações tecnológicas, artísticas e culturais na Europa. Belle Époque é o termo Frances designado para a "beleza da época" traduz a riqueza e liberdade nas artes, bem como o otimismo com as mudanças no transporte, nas comunicações e nas indústrias.

A efervescência nas artes, inspirada no Art Nouveau e em suas linhas - onduladas, figurativas, abstratas ou geométricas - representava delicadeza nos movimentos femininos, a liberdade de expressão e a popularização das artes.

A inclusão de novos materiais impulsionou a produção de objetos decorativos demandados pelas elites ascendentes. Na França, as classes dominantes demandaram por artigos de consumo produzidos por máquinas. "... Para unir a industria com a arte, para mostrar que um móvel, um tecido, um lustre, uma tesoura ou qualquer objeto independentemente de quão simples, é tão digno de atenção por parte do artista quanto uma estátua ou um quadro" (BATTERSBY, 1985). Nesse contexto se acelerou a produção industrial, que uniu as artes com a manufatura de objetos da estética Art Nouveau. O estilo foi 
utilizado na confecção de diferentes artefatos. Dentre eles destacamos os postes da iluminação pública, os lustres e lamparinas que iluminavam os ambientes interiores dos casarões.

No Brasil, uma verdadeira obsessão pela europeização e a modernidade sendo imposta de cima para baixo, diferentemente da Europa, aqui o processo de modernização era conservador, demonstrando no luxo uma fachada "civilizada", mas por dentro uma sociedade ainda atrasada, envolta em um passado colonial e escravista (JUNIOR e FERNANDES, 2013).

A importação dessa modernidade ocorre em regiões mais prósperas como Rio de Janeiro, Amazonas, Minas Gerais, São Paulo e Rio Grande do Sul. As primeiras importações dizem respeito a produtos para abastecer as necessidades de expandir o transporte, como locomotivas e ferrovias, também estruturas para montagem de galpões, mercados, casas, reservatórios e fontes de água, entre outros. Logo os novos materiais chegam às cidades também na forma de peças menores complementando a decoração de praças e construções.

Pelotas segue a tendência das grandes cidades e importa os mais diversos produtos oferecidos pelas industrias europeias, entre eles o Mercado Central, a ponte metálica, o reservatório da Praça Piratinino, chafarizes e postes de iluminação, alem de maquinas, encanamentos utilizados na rede hidráulica e peças de reposição .

\section{A EVOLUÇÃO DA ILUMINAÇÃO}

Inicialmente, a iluminação se deu através da queima de combustíveis a base de óleos animais e vegetais; a irradiação de luz era mínima e trêmula e implicava na sujeira causada pela fuligem e no mau cheiro das fumaças, também contribuía para os riscos de incêndio. Nas ruas "a illuminação pública é também péssimamente feita com azeite de peixe ou kerozene, os lampeões são collocados em taes distancias uns dos outros, que mal illuminão o pequeno círculo em que reverberão os seus enfumaçados raios de luz" (PINHO, 1872, p. 49).

Posteriormente utilizou o gás hidrogênio líquido. Segundo GUTIERREZ (1999), em Pelotas o uso desse combustível se deu a partir de 1853. Em 1875, os serviços passaram a ser explorados por um empresário de Porto Alegre, com capital inglês. A iluminação a gás trouxe certas melhorias, ampliou a eficiência luminosa e, com isso, proporcionou um alargamento na 
vida noturna. Contudo, a necessidade de tubulações encarecia seu uso. O risco de vazamentos, o mau cheiro e a fuligem persistiam.

A iluminação elétrica chegou a Pelotas somente em 1915 (figura 1). Esta evolução tecnológica trouxe mudanças para a economia da localidade. A vida burguesa se estendeu durante o período noturno, em restaurantes, confeitarias, cafés, teatros e cinemas, ampliando o convívio social. Com a chegada da nova tecnologia, também se tornou necessária a substituição dos antigos equipamentos de iluminação a gás, tanto nos postes distribuídos pelas ruas e, mais tarde, nas luminárias chumbadas às fachadas dos edifícios, como no interior dos prédios, que usaram novas lâmpadas, fiações e equipamentos necessários.

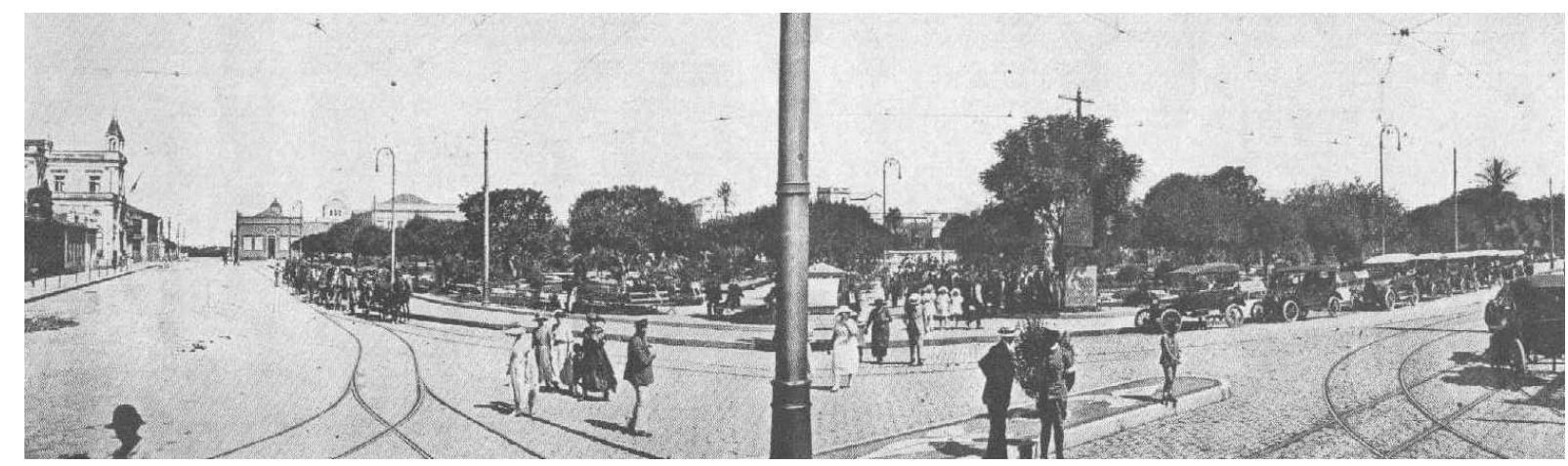

Figura 1- Pelotas, Praça Coronel Pedro Osório.

Fonte: MAGALHÃES, Nelson Nobre. Projeto Pelotas Memória.

\section{MATERIAIS E TÉCNICA}

O século XIX foi um período de ruptura com as técnicas construtivas tradicionais, os metais fundidos e o vidro destacam-se como "novos materiais" e, logo foram amplamente utilizados na arquitetura, em objetos funcionais e ornamentais. Os chamados altos fornos possibilitaram o manuseio dessas matérias no estado líquido. A proximidade das indústrias com as artes promoveu uma diversidade de objetos, possíveis de serem replicados através de moldes, dessa maneira responderam a demanda de bens de consumo.

De acordo com o Centro de Informação Metal Mecânico - CIMM ${ }^{1}$, o processo de fundição aplicou-se a diversos tipos de metais, tais como aços, ferros fundidos, alumínio, cobre, magnésio e respectivas ligas. A fundição do ferro adaptou-se e correspondeu às necessidades da época, o processo foi muito utilizado na produção de objetos no século XIX.

\footnotetext{
${ }^{1}$ Disponível em: <http://www.cimm.com.br/portal/noticia/material_didatico/3676>. Acesso em: 16/02/2007
} 
No Brasil, houve no final do mesmo século, a implantação de empresas de fundição inglesas, com a intenção de absorver a demanda local. Entretanto, sua produção se restringia a confecção de equipamentos para as ferrovias e da construção civil (GOMES, 1987). Os utensílios decorativos ainda eram importados de países como a Inglaterra, a França e a Alemanha. Algumas empresas nacionais persistiram por mais algumas décadas, uma das quais se encontra citada nesse artigo.

\section{A PESQUISA DOS ELEMENTOS DE ILUMINAÇÃO URBANA}

Por uma questão de síntese, neste artigo serão apresentados os modelos que se repetem em maior número na cidade, em postes e em luminárias fixadas nas fachadas (tocheiros). A área definida para a investigação dentro do perímetro urbano compreende as atuais zonas de proteção do patrimônio cultural (ZPPCs). ${ }^{2}$ A partir desse recorte se desenvolveu a pesquisa de campo, documentando cada exemplar, as repetições no local, tamanho, modelo, cor, conservação, e sua utilização (funcional ou decorativa). A grande maioria ainda está sendo usada, a falta de manutenção decorreu no não funcionamento de outras peças. A localização desses artefatos encontra-se dentro das quatro Zppcs. Mas, grande parte está na segunda zona. (Figura )
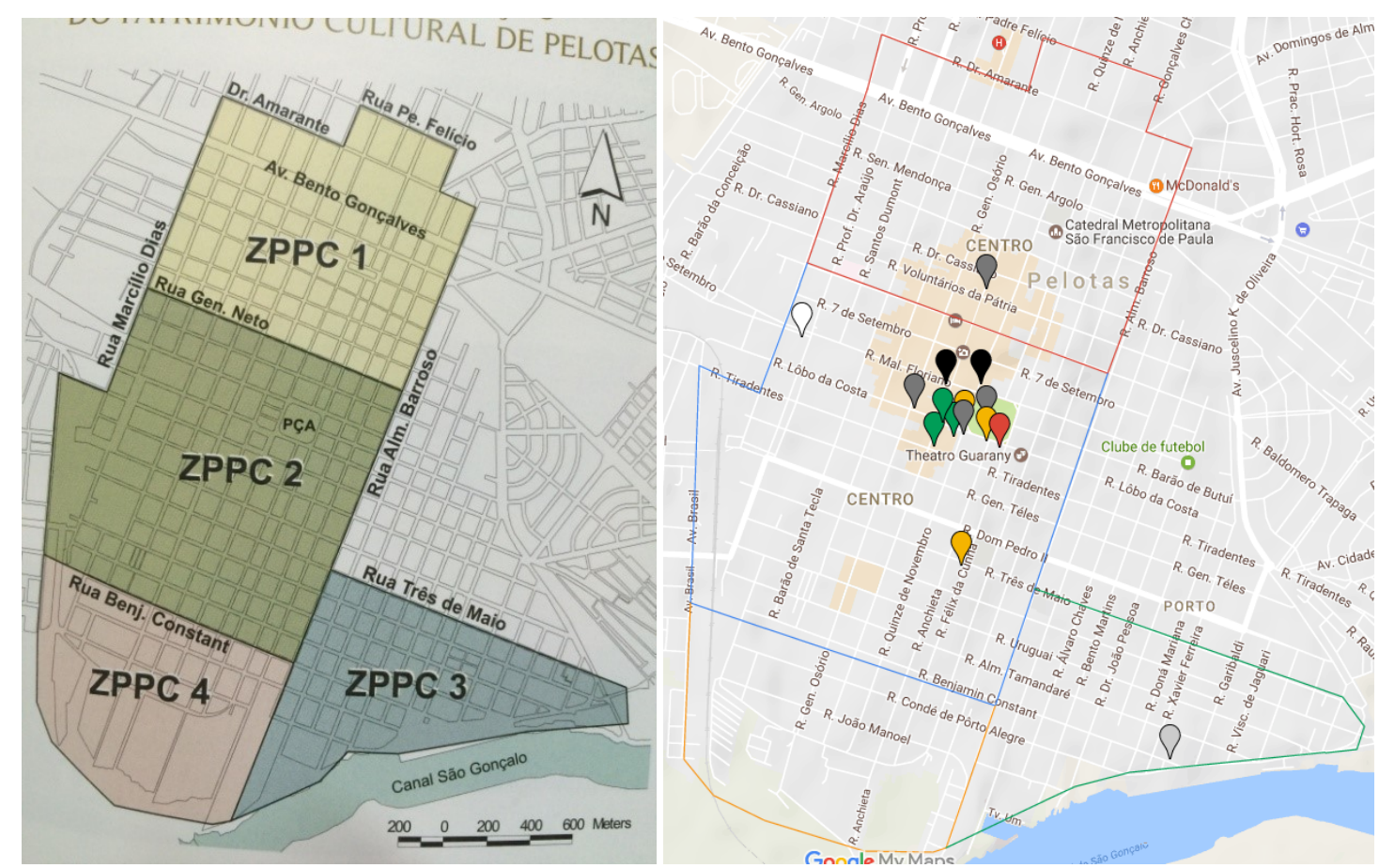

Figura 2: à esquerda as Zonas de Proteção do Patrimônio Cultural 1,2,3 e 4. Fonte: Secult. À direita disposição das luminárias dentro do mapa. Fonte: do autor

\footnotetext{
${ }^{2}$ Áreas determinadas a partir da lei municipal 4568/200 e buscam manter a integridade das áreas da cidade com características históricas e culturais, significativas para sua identidade (SECULT 2008).
} 


\section{POSTES DO CHAFARIZ DAS NEREIDAS}

Em 1872 a cidade ainda não possuía um sistema de abastecimento de água potável ao público, o fornecimento ocorria por meio de poços em casas, cisternas para acumular água da chuva e pela distribuição feita pelos aguadeiros (XAVIER, 2006). Entre 1872 e 1975 foram instalados os encanamentos em ferro fundido, os chafarizes e os postes (figura 2) para abastecimento.

Os chafarizes foram acertados em contrato feito entre a prefeitura de Pelotas e a companhia Hidráulica Pelotense. Consta nos arquivos da companhia que entre as obrigações do contratado, a instalação de um reservatório e de quatro chafarizes em pontos estratégicos da cidade para que os moradores utilizassem do abastecimento. Também estava estipulada a presença de torneiras que facilitassem o ato de encher vasilhames, e ainda, que os locais deveriam possuir iluminação para abastecimento noturno.

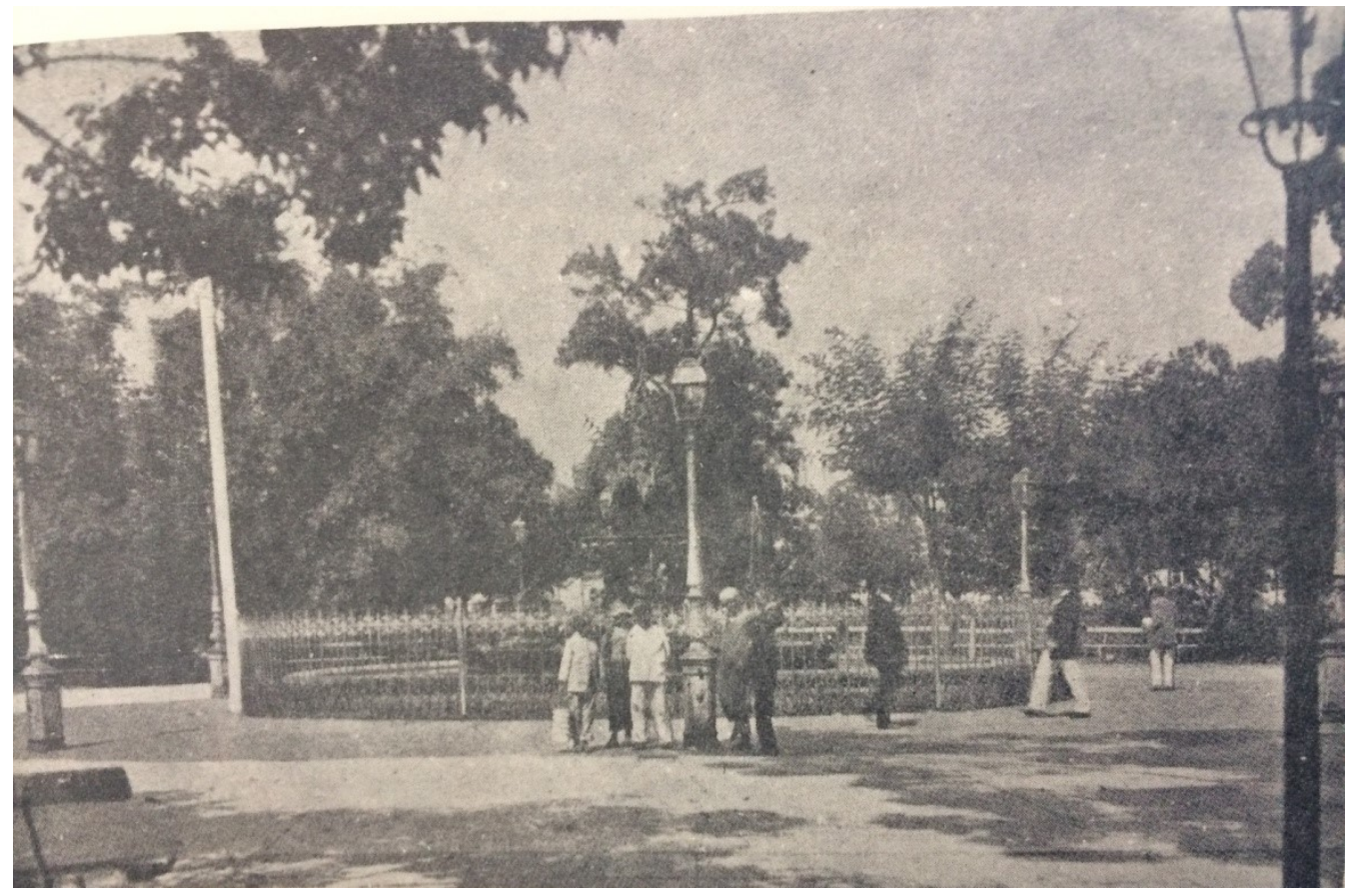

Figura 2 Chafariz da praça Cel. Pedro Osório

Fonte: Museu da Luz - Porto Alegre.

$\mathrm{Na}$ época, as tubulações para abastecer a iluminação a gás e o sistema hidráulico eram em ferro fundido, bem como os postes que ainda eram decorados com ornamentações em alto relevo com motivos da fauna, flora e decorações geométricos. A empresa de fundição 
escolhida foi a de Antoine Durenne, proveniente da França, e seu modelo era encontrado em catálogos da época (figura 3).

Conforme as obrigações de contrato citadas anteriormente, deveria o contratado, entre outras coisas, disponibilizar torneiras e candelabros nos chafarizes. No chafariz das Nereidas, situado no centro da Praça Coronel Pedro Osório, o modelo dos postes que complementam a fonte contemplavam as duas funções. Ou seja, possuíam encanamento interno de rede hidráulica, e, em uma das faces, um mecanismo que liberava a passagem de água (torneiras), assim como um encanamento para o gás utilizado na iluminação, até a luminária existente na parte superior do poste (candelabros).

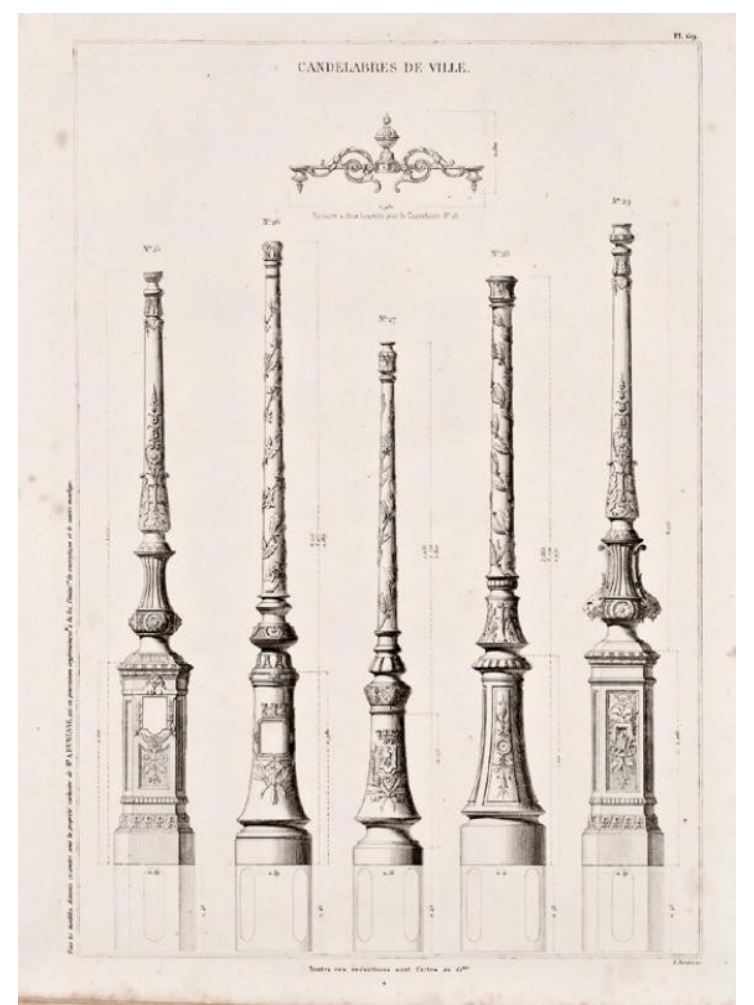

Figura 3 pagina de catálogo da Fundição A. Durenne, o primeiro à direita com as mesmas características de relevos e tamanho.

Fonte : https://e-monumen.net/patrimoine-monumental/dur_1868_pl159-candelabres-deville/

Os requintes da Belle Époque encontrados nesses artefatos estão nos desenhos em relevo que destacam a elegância da época, enriquecidos com a feminilidade das formas. Os ornatos são inspirados na natureza, com ramos e folhagens, acantos e flores. As linhas são sinuosas e os arranjos exploram a simetria na disposição faz formas e nos complementos 
geométricos (figura 5). Destacando-se ainda uma gárgula localizada na saída da água e dois leões forjados separadamente e agregados ao poste.

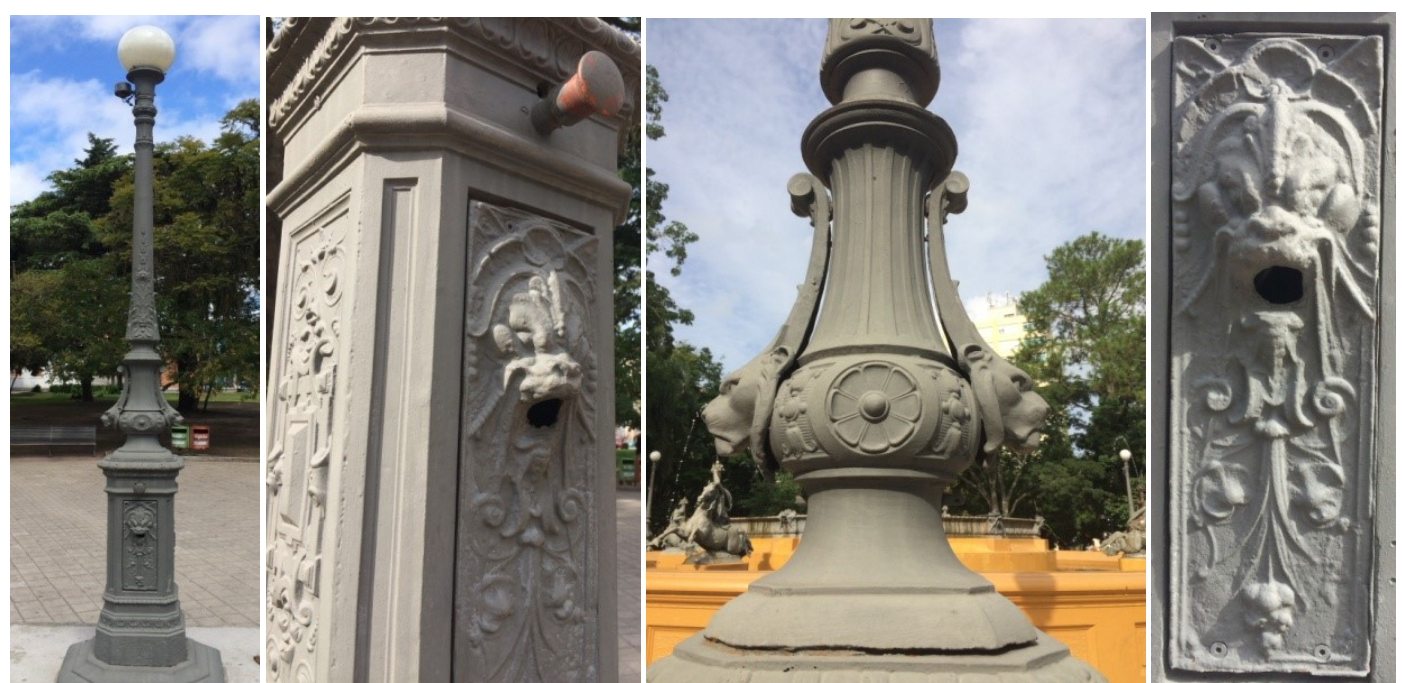

Figura 4: da esquerda para direita: o poste, mecanismo para acionar a saída de água, as cabeças de leões, a gárgula.

Fonte: do autor

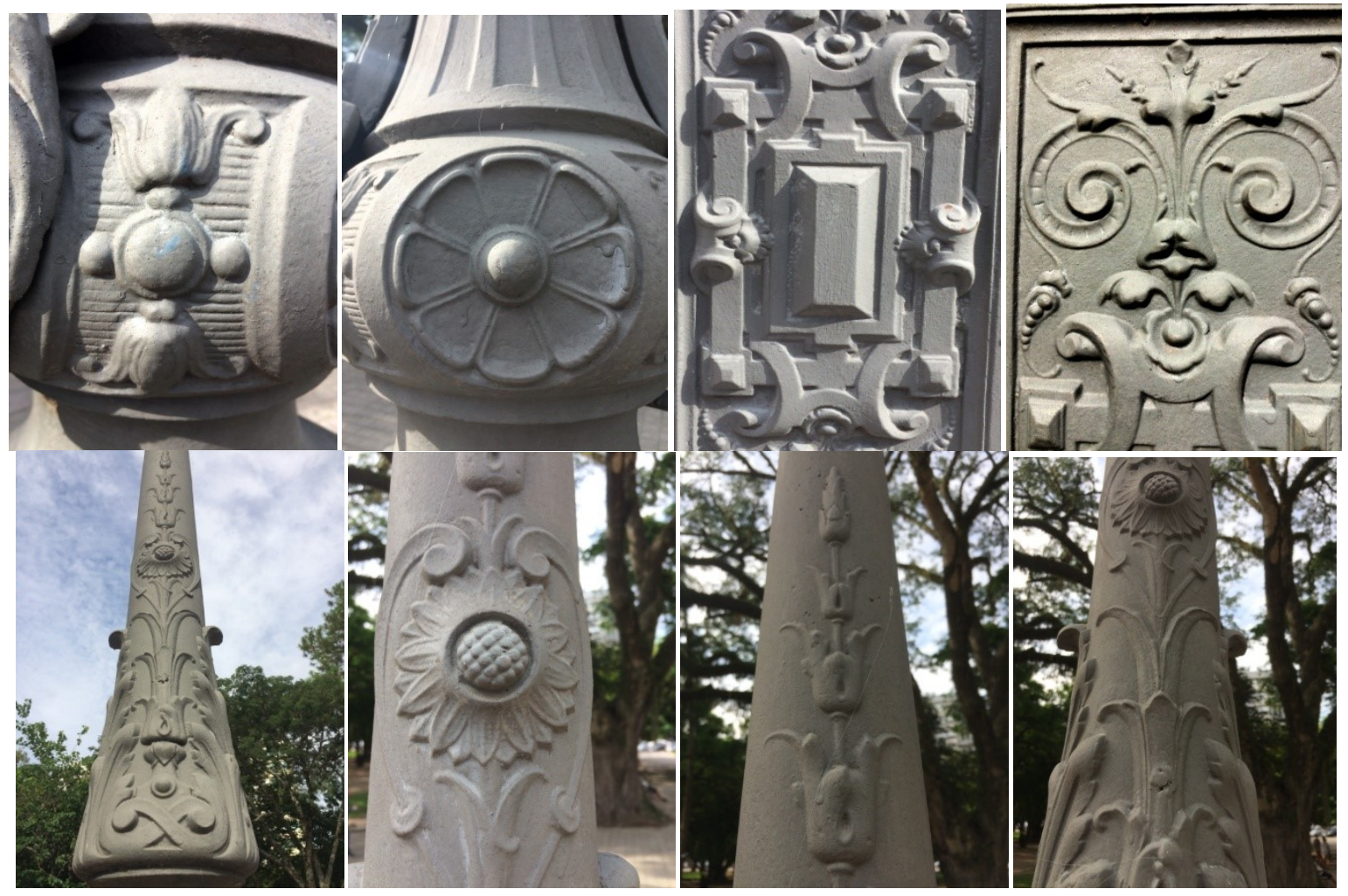

Figura 5: imagens da decoração em relevo Fonte: do autor 


\section{LUMINÁRIAS EM FACHADAS}

Segundo MAGALHÃES (1993 p. 91), a partir da década de 1890, com o declínio do charque e o aumento da população urbana, a economia da cidade se direciona para outros setores: a indústria e o comercio. Pelotas passou a realizar operações comerciais e financeiras promovendo a construção de prédios destinados a sediar bancos, hotéis, clubes e teatros.

O período entre 1900 e 1930 é, tanto quantitativamente quanto qualitativamente, bastante significativo para a arquitetura da cidade. Se, no período anterior (1850 a 1900) existiu um período chamado de ecletismo historicista, a partir do século XX ocorreu uma tendência a favor do ecletismo tipológico, que implica em escolhas prévias de cunho analógico ou de referência, que orientam o estilo quanto à finalidade a que se destina $o$ edifício a ser construído (SCHLEE, 1993).

Hoje, muitas dessas construções encontram-se preservadas. As luminárias de fachada foram encontradas, coincidentemente, nos frontispícios de prédios públicos ou em construções e reformas executadas entre 1900 e 1930. A disposição destes locais está incluída dentro das ZPPCs, contudo, sua grande maioria está na segunda zona.

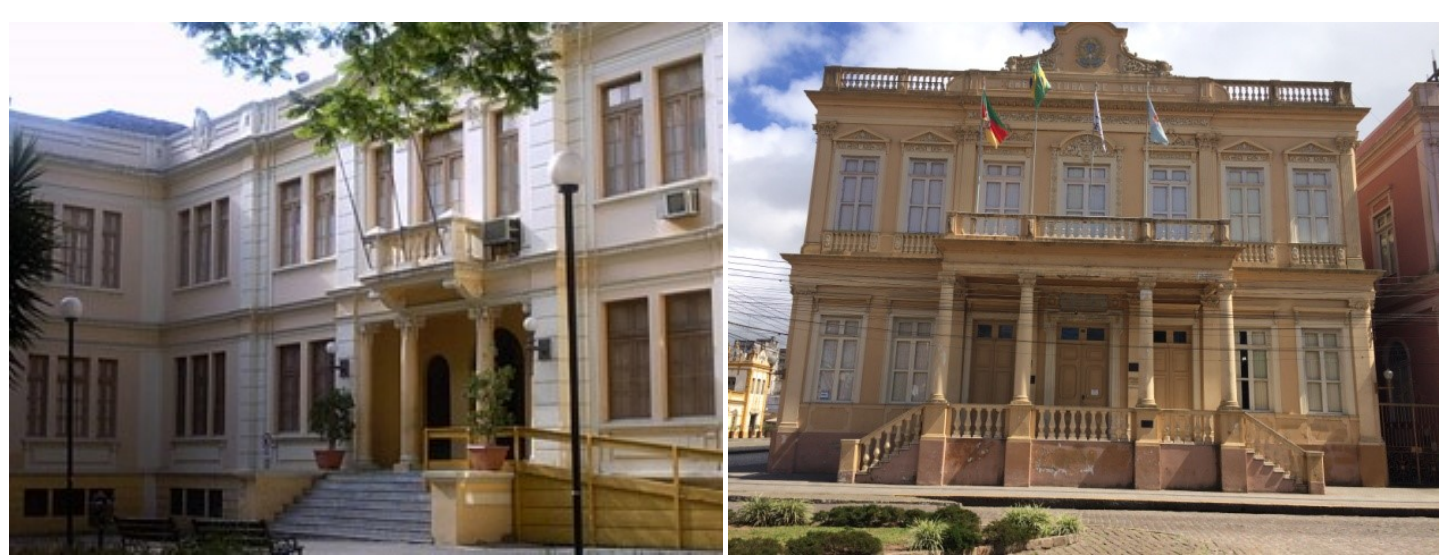

Figura 6- a esquerda o prédio da Faculdade de Direito e suas luminárias nos lados da entrada, a edireita o prédio da Prefeitura de Pelotas com as luminárias colocadas nas duas esquinas frontais da construção.

Fonte: do Autor 


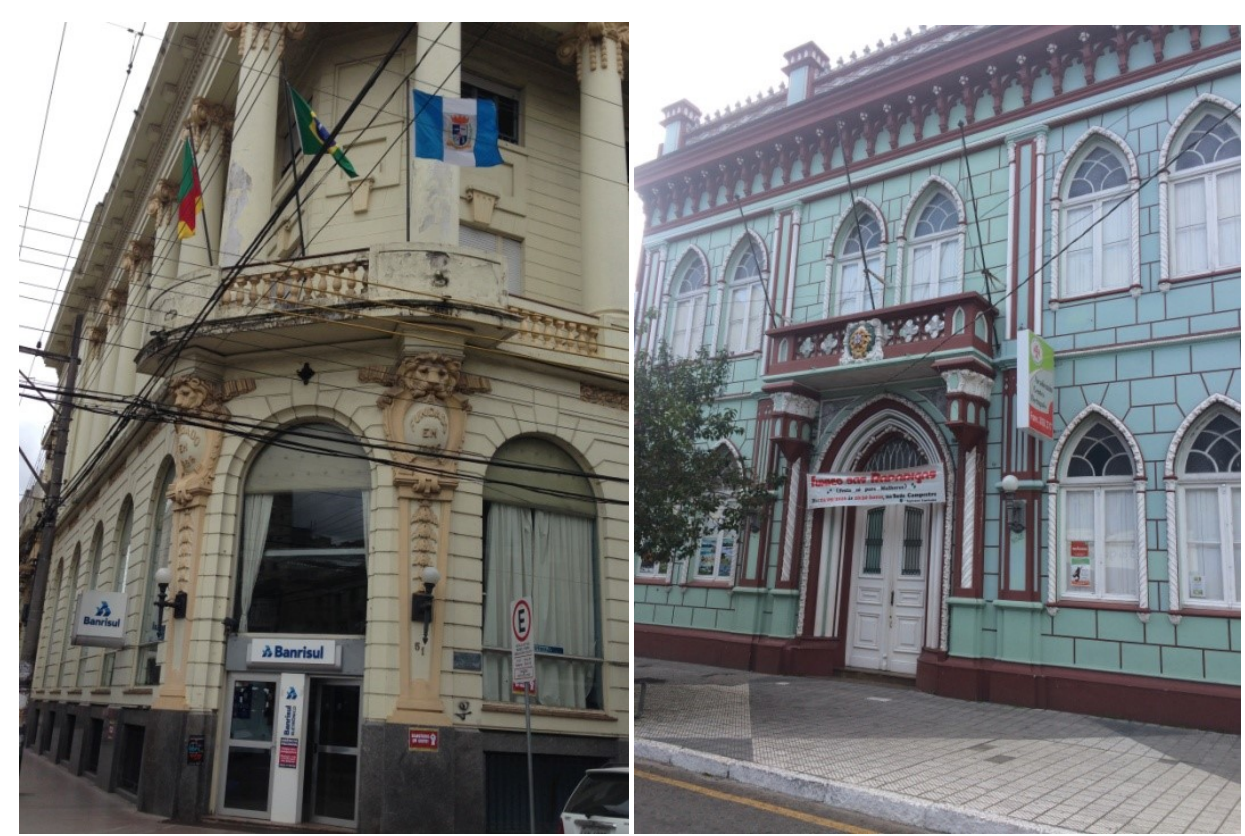

Figura 7: A esquerda, hoje Banrisul, construído para agencia do Banco Pelotense; à direita $\mathrm{O}$ clube Centro Português localizado no mesmo prédio desde sua construção. Em ambos as luminárias estão ao lado da porta de entrada.

Fonte: do autor

Estes modelos foram projetados para a utilização de energia elétrica, confeccionados em ferro ou alumínio fundido e com candelabros de vidro. São fixas às fachadas e colocadas em locais de destaque, próximas de grandes portas ou nas esquinas dos prédios (figuras 6 e 7). As luminárias fixas em fachadas foram outros modelos encontrados na pesquisa, são comumente chamadas de tocheiros, por sua forma que lembram tochas. Os artefatos encontrados pela cidade são suspensas por um braço fixo a uma base. Dividiremos em dois modelos: Tocheiro A e tocheiro B (figura 8).

As informações referentes à fabricante e a datação das peças ainda estão sendo investigados. Foi encontrado em um dos tocheiros A, uma tarjeta com o nome da fundição e cidade de procedência: Nova Fundição Guanabara - Rio de Janeiro (figura 8). Casualmente todos os exemplares de tocheiro B possuem a seguinte marca em relevo: Um logotipo em forma triangular com as letras NFG (figura 10), deduz-se que essas letras sejam iniciais da mesma fundição encontrada no modelo A. 


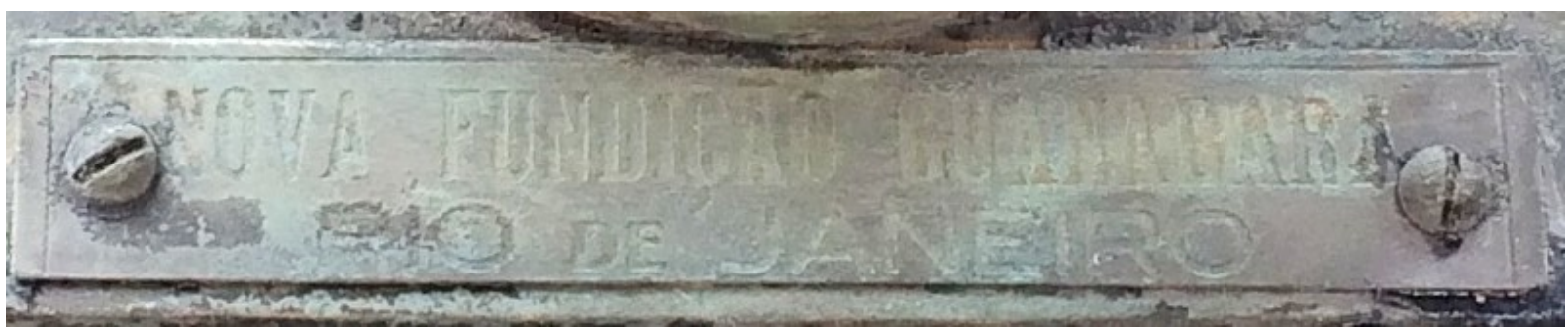

Figura 8: Plaqueta do fabricante e procedência

Fonte - do autor

Esta empresa de fundição deixou de existir e as informações por enquanto encontradas foram em um almanaque do ano de 1929, (figura 9).
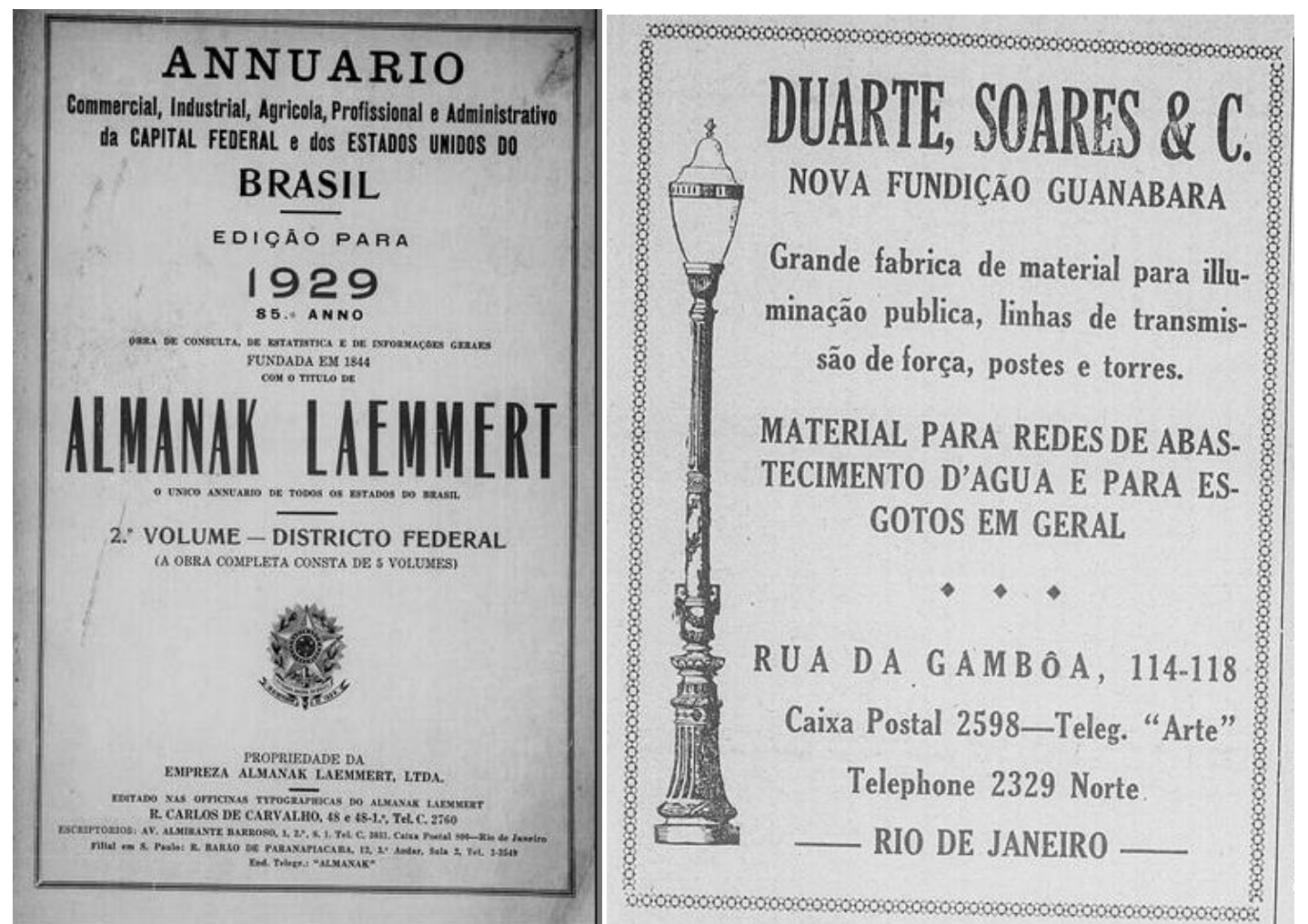

Figura 9: na imagem a esquerda o Almanaque com a publicidade da época, na imagem a direita a propaganda da fundição utilizada no almanaque do ano de 1929.

Fonte:

http://memoria.bn.br/DocReader/Hotpage/HotpageBN.aspx?bib=313394\&pagfis=102189\&ur l=http://memoria.bn.br/docreader\# 


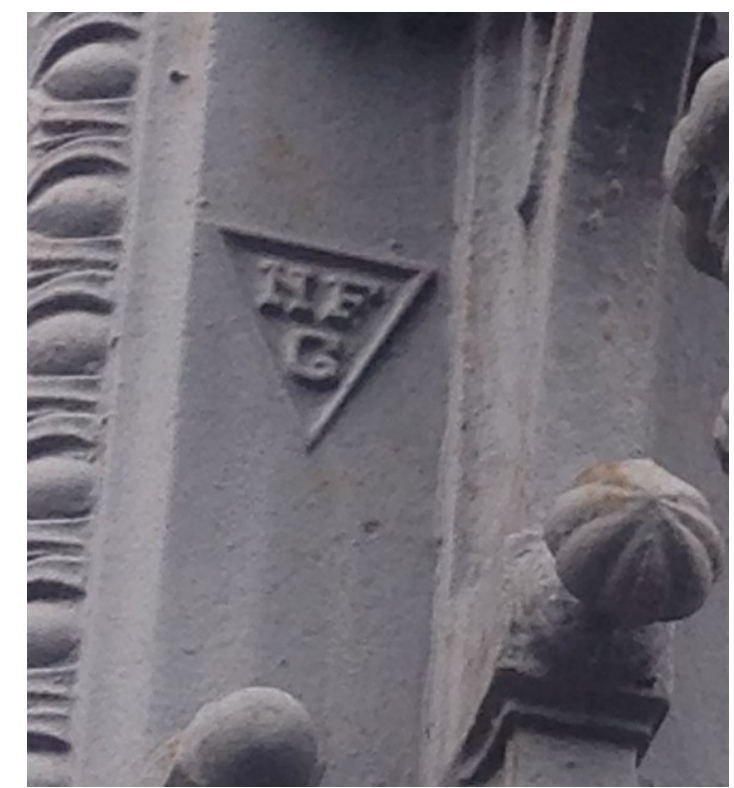

Figura 10: logotipo encontrado em todos os tocheiros B Fonte: Do autor

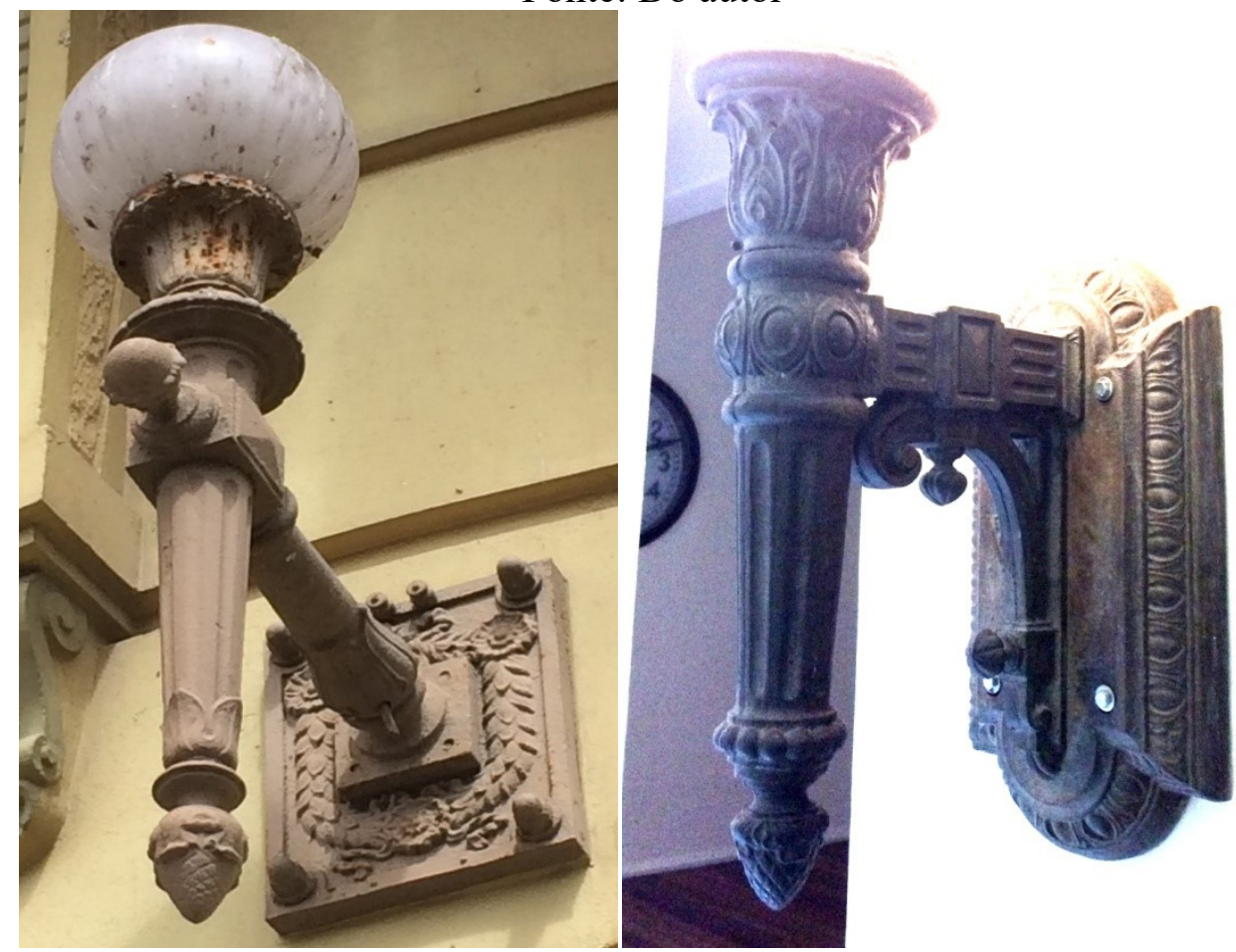

Figura 11: tocheiros - à esquerda o tocheiro $\mathrm{A}$, à direita o tocheiro $\mathrm{B}$. Fonte: do autor

Esses tocheiros possuem desenhos em alto televo complementando suas formas. Podem ser observadas muitas folhagens, pinhas, formas geométricas e simetria na disposição dos relevos, tanto nas tochas quanto nos braços e nas bases de sustentação (figuras 12, 13). 


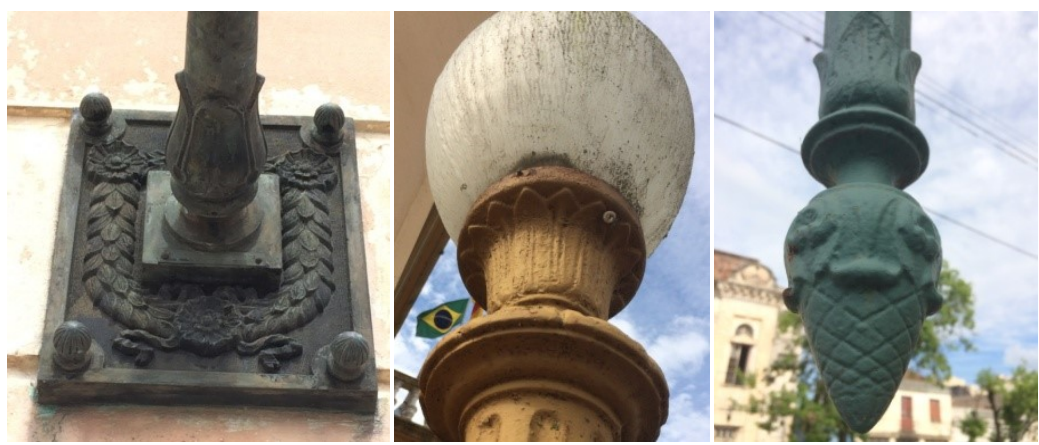

Figura 12: decorações em relevo no tocheiro A.

Fonte: do autor

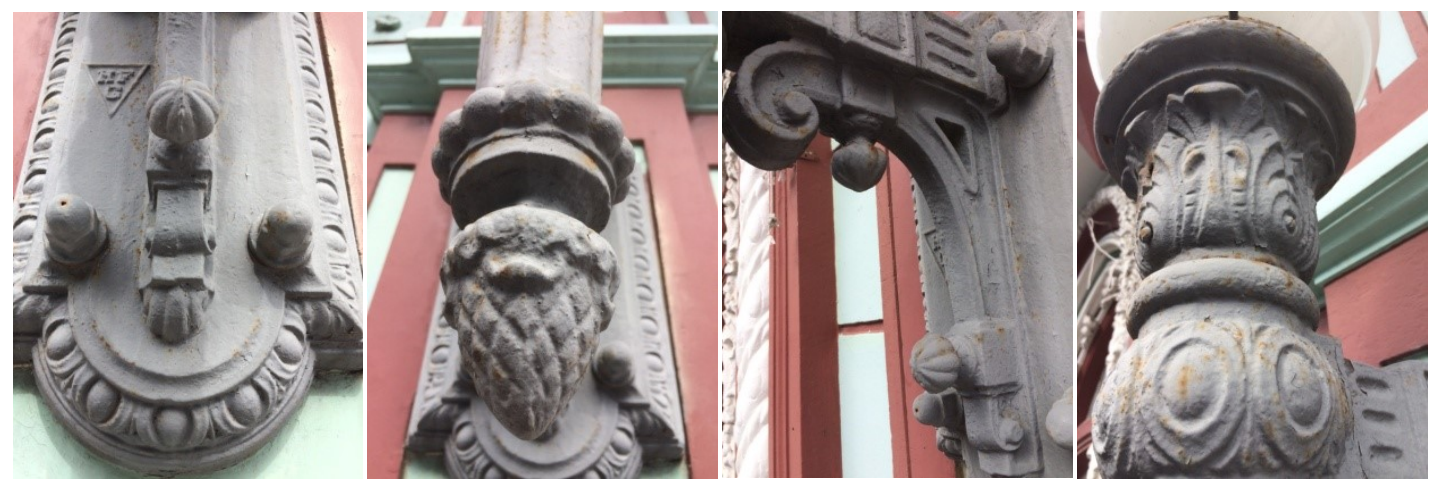

Figura 13 Decorações em relevo no tocheiro B

Fonte: do autor

\section{CONCLUSÃO}

Todos esses exemplos são bens integrados a construção arquitetônica ou espaços urbanos. Eles possuem a materialidade, o estilo dos ornamentos e as datações, que, creditam a esses objetos de iluminação urbana uma considerável representação da Belle Èpoque na cidade. Sua presença evidencia as transformações em busca da modernidade do final do século XIX e inicio do XX, e, replicada na cidade de Pelotas. Assim sendo, possui importância para a sofisticação dos prédios, complementam do conjunto urbano e histórico já preservado e contribuindo para a preservação da memória.

As Leis nacionais redigidas pelos técnicos do IPHAN e as normativas municipais da SECULT discorrem sobre a proteção destes bens patrimoniais. Porém, os elementos que eram utilizados nas ruas, hoje não existem mais. Nas praças e fachadas das construções estão desaparecendo, outras se encontram fragmentados por falta de conservação ou vandalismo. 
Em Pelotas são poucas as pesquisas realizadas na área, esta pesquisa visa unir-se a outras, assim, objetivam o reconhecimento dos valores dos bens integrados à arquitetura, que complementam o patrimônio cultural da cidade.

\section{REFERÊNCIAS}

BATETERSBY, Martin. Art Nouveau. Rio de Jaeneiro. Ao Livro Técnico S/A - Industria e Comércio. 1985

GOMES, Geraldo. Arquitetura do Ferro no Brasil. São Paulo: Nobel, 1987

JÚNIOR, Sérgio Luiz Milagre; FERNANDES, Tabatha de Faria. A Belle Époque Brasileira: as transformações urbanas no Rio de Janeiro e a sua tentativa de modernização no século XIX. História em Curso, Belo Horizonte, v. 3, n. 3, p. 19-33, mai. 2013. ISSN 21781044.

Disponível

em:

$<$ http://periodicos.pucminas.br/index.php/historiaemcurso/article/view/5337>. Acesso em: 16 fev. 2017.

PINHO, A Augusto de. Uma Viagem ao sul do Brasil. Rio de Janeiro: Tip. De F. A. de Souza, 1872

SECULT. Manual do usuário de imóveis inventariados. Prefeitura Municipal de Pelotas. Pelotas: Nova Prova, 2008.

TURGEON Laurier, La Mèmorie de la Culture Materiele et La Culture Matériele de La Mèmorie. Disponível em: culturehttps://mail.google.com/mail/u/0/\#inbox/156937d446a35e40?projector=1. acesso em 05 mar. 2017.

XAVIER, Janaina S. Chafarizes e Caixas d'água de Pelotas Monografia. Pós graduação em Artes, UFpel, 2006.

SANTOS, Carlos Alberto A. Ecletismo na fronteira meridional do Brasil: 1870-1931. Tese (Doutorado em Arquitetura e Urbanismo - Área de Conservação e Restauro) Faculdade de Arquitetura e Urbanismo da Universidade Federal da Bahia, 2007.

http://www.cimm.com.br/portal/noticia/material_didatico/3676>. Acesso em: 16 fev. 2017 